\title{
Pharmacokinetics and antitumor efficacy of DSPE-PEG2000 polymeric liposomes loaded with quercetin and temozolomide: Analysis of their effectiveness in enhancing the chemosensitization of drug-resistant glioma cells
}

\author{
JUN HU $^{1,3^{*}}$, JUNJIE WANG $^{2 *}$, GANG WANG $^{2}$, ZHONGJUN YAO ${ }^{3}$ and XIAOQIAN DANG ${ }^{1}$ \\ ${ }^{1}$ The Second Affiliated Hospital of Xi'an Jiaotong University, Xi'an, Shanxi 710004; \\ ${ }^{2}$ Department of Pharmaceutics, Shanghai Eighth People's Hospital, Shanghai 200235; \\ ${ }^{3}$ Taihe Hospital, Hubei University of Medicine, Shiyan, Hubei 442000, P.R. China
}

Received April 18, 2015; Accepted December 16, 2015

DOI 10.3892/ijmm.2016.2458

\begin{abstract}
In the present study, a new type of DSPE-PEG2000 polymeric liposome for the brain-targeted delivery of poorly water-soluble anticancer drugs was successfully prepared and characterized. The nanoparticles were formed by the self-assembly of an amphiphilic polymer consisting of hydrophilic 1,2-distearoyl-sn-glycero-3-phosphoethanolamineN-[methoxy(polyethylene glycol)-2000] (DSPE-PEG2000). These nanoliposomes served as a safe delivery platform for the simultaneous delivery of quercetin (QUE) and temozolomide (TMZ) to rat brains. The 2-in-1 PEG2000-DSPE nanoliposomes containing QUE and TMZ (QUE/TMZ-NLs) were rapidly taken up by the $\mathrm{U} 87$ glioma cells in vitro, whereas at the same concentrations, the amounts of the free drugs taken up were minimal. The QUE/TMZ-NLs showed an enhanced potency in the U87 cells and the TMZ-resistant U87 cells (U87/TR cells), possibly due to the high intracellular drug concentration and the subsequent drug release. In vivo biodistribution experiments revealed a significant accumulation of QUE/TMZ-NLs in the brain, with significantly increased plasma concentrations of QUE and TMZ, as well as delayed clearance in our rat model of glioma. The results were not so significant for the QUE-loaded nanoliposomes (QUE-
\end{abstract}

Correspondence to: Dr Gang Wang, Department of Pharmaceutics, Shanghai Eighth People's Hospital, 8 Caobao Road, Shanghai 200235, P.R. China

E-mail: wangan139@163.com

Dr Xiaoqian Dang, The Second Affiliated Hospital of Xi'an Jiaotong University, 157 Xiwu Road, Xi'an, Shanxi 710004, P.R. China

E-mail: dieryiyuan@163.com

${ }^{*}$ Contributed equally

Key words: quercetin, temozolomide, DSPE-PEG2000 polymeric liposome, glioma, multidrug resistance, drug delivery
NLs) and free TMZ. The findings of our study establish the DSPE-PEG2000 polymeric liposome as a novel and effective nanocarrier for enhancing drug delivery to brain tumors.

\section{Introduction}

Brain tumors are one of the most challenging diseases to treat and there remains an unmet medical need for effective treatments. Chemotherapy often fails due to the insufficient accumulation of drugs in the tumor sites and the subsequent development of drug resistance. Strategies for the reversal of resistance involve the inhibition of enzymes responsible for the efflux of drugs, the modulation of proteins regulating apoptosis, and the improvement of drug uptake using nanotechnologies. Over the past decade, there have been momentous developments in drug delivery systems, particularly in the use of nanotechnology-based delivery systems.

Polymeric liposomes have the advantage of being the least toxic for in vivo applications. Over the past decace, significant progress has been made in the delivery of DNA/RNA and small-molecule drugs (1-3). Multiple liposome formulations have been used clinically in the treatment of cancer and infectious diseases (4), and their applications in other diseases are currently being investigated in clinical trials (5). The development of clinically suitable liposome formulations has resulted from two major technological achievements: i) the inclusion of PEGylated lipids in the liposomes for the purposes of bypassing the reticuloendothelial system, resulting in significant drug accumulation in tumors $(6,7)$; and ii) the strategic development of a remote drug-loading process based on the ammonium sulfate gradient method, to achieve significantly high quantities of drugs in the liposomes (8). We have previously demonstrated that the 1,2-distearoyl-sn-glycero-3-phosphoethanolamine-N[methoxy(polyethylene glycol)-2000] (DSPE-PEG2000)coated and quercetin (QUE)-loaded nanoliposomes (QUENLs) exhibited a hydrophilic layer on the surface, resulting in particle size increment, positive zeta $\zeta$-potential, and enhanced physical stability $(9,10)$. Notably, DSPE-PEG2000 coating of particles is a simple and flexible technology used to alter the 
surface properties of liposomes, and is expected to have broad applications in anticancer drug delivery systems.

It has been previously demonstrated that QUE, as a potential chemopreventer, suppresses cancer cell growth, proliferation and metastasis, as well as the expression of mutant p53 (11), and also enhances death receptor-mediated apoptosis in glioma cells $(12,13)$. QUE is considered a potent free radicalscavenging antioxidant owing to its abundant hydroxyl groups and conjugated $\mathrm{p}$ orbitals, which donate electrons or hydrogens, and scavenge $\mathrm{H}_{2} \mathrm{O}_{2}$ and superoxide anions (14). QUE-mediated apoptosis may result from the induction of stress proteins, the disruption of microtubules, the stimulation of the release of cytochrome $c$ and the activation of caspases (15-17), thus rendering QUE a promising candidate for cancer prevention and therapy. A recent study reported that the combination of QUE and temozolomide (TMZ), a FDA-approved drug for brain cancer treatment, exerted a synergistic effect in brain tumors in vitro (18).

In a previous study of ours (10), we reported that QUE/ DSPE-PEG2000 showed significantly enhanced potency in glioma in vitro compared to free QUE. The aim of the present study was to evaluate the application of DSPE-PEG2000 as a nanocarrier for the combined delivery of QUE and TMZ for the treatment of glioma. We investigated the physicochemical properties, the release and clearance profiles, the biodistribution and the enhanced potency of QUE/TMZ-NLs in human U87 glioma cells and TMZ-resistant U87 cells (U87/TR cells), providing novel and significant insight into the application of QUE/TMZ-NLs for the treatment of brain tumors.

\section{Materials and methods}

Reagents and cell lines. DSPE-PEG2000 was purchased from Nippon Oil and Fats Co., Ltd., (Tokyo, Japan). Poloxamer 188 was purchased from BASF Aktiengesellschaft (Limburgerhof, Germany). Cholesterol and soy lecithin were purchased from Shanghai Youngsun Foods Co., Ltd. (Shanghai, China). Tween-80 was purchased from Shanghai Chemical Reagent Co., Ltd. (Shanghai, China). Glyceryl behenate (Compritol ATO 888) was purchased from Gattefosse S.A. (Saint-Priest, France). QUE was purchased from the National Institute for the Control of Pharmaceutical and Biological Products (NICPBP; Beijing, China). TMZ was purchased from Jiangsu Tasly Diyi Pharmaceutical Co., Ltd. (Jiangsu, China). Annexin V and proridium iodide (PI) were obtained from BestBio Biotechnologies Co., Ltd. (Shanghai, China). RPMI-1640, penicillin-streptomycin, trypsin-ethylenediaminetetraacetic acid (EDTA) and fetal bovine serum (FBS) were obtained from Gibco BRL/Life Technologies (Carlsbad, CA, USA). U87 glioma cells were obtained from the American Type Culture Collection (ATCC; Rockville, MD, USA).

Preparation of QUE/TMZ-NLs and QUE/TMZ-FITC-NLs. Both the QUE/TMZ-NL and the QUE/TMZ-FITC-NL suspensions were prepared by emulsification-evaporation and low temperature curing preparation as previously described (19). The aqueous phase consisted of poloxamer 188 and Tween-80 (1:1, w/v), dissolved in pure water and maintained in a water bath at $75^{\circ} \mathrm{C}$. DSPE-PEG2000 dissolved in methanol $(5.0 \mathrm{mg}$ in $1.0 \mathrm{ml})$ was added dropwise into the aqueous phase with rapid stirring $(1,000 \mathrm{rpm} / \mathrm{min})$. The mixture was stirred for $30 \mathrm{~min}$ in a bath sonicator until the solution became brown/black and translucent. To remove the methanol, the solution was concentrated in a rotary evaporator at $70^{\circ} \mathrm{C}$ to $3.0 \mathrm{ml}$. The oil phase mainly consisted of glyceryl behenate, soy lecithin and cholesterol (1:2:1, w/w/w), and in addition, glyceryl behenate and cholesterol were melted in a water bath at $80^{\circ} \mathrm{C}$. QUE, TMZ and soy lecithin $(1: 1: 1, \mathrm{w} / \mathrm{w} / \mathrm{w})$ were dissolved in the ethanol-acetone $(1: 1, \mathrm{v} / \mathrm{v})$ solvent, and the oil phase of the aforementioned mixed solvent was then injected into the aqueous phase through plastic needle tubing (internal diameter, $0.45 \mu \mathrm{m}$; injection rate, $2.0 \mathrm{ml} / \mathrm{min}$ ) under mechanical agitation at $1000 \mathrm{rpm}$. After stirring for $2 \mathrm{~h}$, the liposomal suspension was cured at low temperatures of $0-4^{\circ} \mathrm{C}$ under mechanical agitation at $800 \mathrm{rpm}$. The suspension was then filtered through dialysis tubing to remove any unincorporated drugs. Briefly, the QUE/TMZ-NLs were injected into the dialysis tubing and the dialysis tubing was washed in mannitol solution and dialyzed 3 times to remove free QUE or TMZ ( $2 \mathrm{~h}$ for the first and the second washes, and $12 \mathrm{~h}$ for the third wash at $\left.0-4^{\circ} \mathrm{C}\right)$. Finally, the purified QUE/TMZ-NLs were obtained and stored at $0-4^{\circ} \mathrm{C}$. The QUE/TMZ-FITC-NLs were prepared by the addition of $200 \mu \mathrm{l}$ QUE/TMZ-FITC suspension to the liposomes. The mixture was sonicated in a water bath using a laboratory ultrasonic device at $250 \mathrm{~Hz}$ for $10 \mathrm{~min}$. Prior to use in the cell experiments, the prepared QUE/TMZ-NLs were suspended in RPMI-1640 medium containing 10\% (v/v) FBS using ultrasound. The control liposomes were also prepared using the same method without adding QUE or TMZ at any stage of the preparation process.

Characterization. The size and polydispersity index of the QUE/TMZ-NLs were determined using photon correlation spectroscopy with the use of a laser particle analyzer (Jinan Rise Science \& Technology Co., Ltd). The $\zeta$-potential was analyzed using a microscopic electrophoresis system (DXD-II; Jiangsu Optics Co., Ltd., Jiangsu, China) at $25^{\circ} \mathrm{C}$. The morphology of the cells treated with the QUE/TMZ-NLs was observed under a transmission electron microscope (TEM-1200EX; JEOL Ltd., Tokyo, Japan). The samples were dissolved in deionized water contained in $1.0 \mathrm{ml}$ quartz cuvettes, and the UV data were collected using a T90 UV-VIS spectrophotometer (Beijing Purkinje General Instrument Co., Ltd., Beijing, China). The concentration of the QUE/TMZ-NLs was then determined by the absorbance measured at 365 and $329 \mathrm{~nm}$, by high-performance liquid chromatography (HPLC), using the experimentally determined extinction coefficient of $0.0101 \mathrm{1} / \mathrm{mg}$.

Fourier transform infrared spectroscopy (FTIR). Infrared spectra of QUE, QUE-NLs, TMZ and QUE/TMZ-NLs were recorded on a FTIR spectrophotometer (PerkinElmer, Inc., Waltham, MA, USA) by the KBr disk method from 4,000 to $500 \mathrm{~cm}^{-1}$.

Entrapment efficiency (EE) and drug loading. The free drugs were separated from the QUE/TMZ-NLs using a centrifugation technique for the measurement of EE. Briefly, the QUE/TMZ-NLs were diluted in $1.0 \mathrm{ml}$ purified water and centrifuged at $16,000 \times \mathrm{g}$ for $15 \mathrm{~min}$, and the supernatant containing free drugs was collected, and adjusted to a 
volume of $10 \mathrm{ml}$ with ethanol for further analysis. A solution of $10 \%$ Triton $\mathrm{X}$-100-ethanol $(0.5 \mathrm{ml})$ was then added and incubated for $5 \mathrm{~min}$ to breakdown the liposomes and dissolve the QUE and TMZ. The mixture was then centrifuged at $16,000 \times \mathrm{g}$ for $10 \mathrm{~min}$. The loading content and EE of QUE in the QUE/TMZ-NLs was analyzed by HPLC (Dionex Utimate 3000 HPLC System with an AD20 dual absorbance detector and computer; Thermo Fisher Scientific Inc., Sunnyvale, CA, USA) at $254 \mathrm{~nm}$. The loading content and EE of TMZ in the QUE/TMZ-NLs were measured at $329 \mathrm{~nm}$. A Diamond C18 column was used with the flow of $1.0 \mathrm{ml} /$ min for the eluent [methanol/0.5\% acetic acid (10:90)] during 0-19 min. The loading content was calculated as follows: loading content $(\%)=$ (weight of drug in the nanoparticles/ weight of nanoparticles) $\mathrm{x} 100$. The EE was calculated as follows: $\mathrm{EE}(\%)=$ weight of drug in the nanoparticles/weight of the feeding drug x100.

In vitro release assay. The QUE/TMZ-NLs were dispersed in $2.0 \mathrm{ml}$ of $10 \%(\mathrm{v} / \mathrm{v})$ human plasma in phosphate-buffered saline (PBS). Each suspension was incubated with gentle shaking at $37^{\circ} \mathrm{C}$ throughout the experiment. At designated intervals, an aliquot $(500 \mu \mathrm{l})$ was withdrawn and centrifuged at $5,000 \mathrm{x} \mathrm{g}$ for $5 \mathrm{~min}$ at $4^{\circ} \mathrm{C}$. After collecting the supernatant, the pellet of nano/microspheres were resuspended in the same volume of fresh release medium $(500 \mu \mathrm{l})$, and then returned to the sample suspension. The amounts of QUE or TMZ in the supernatant were determined by HPLC as described above.

Cellular uptake of QUE/TMZ-NLs. The uptake of QUE/TMZ-NLs by the U87 cells was analyzed by confocal fluorescence microscopy. The U87 cells were plated on two 4-well chamber slides at a density of 40,000 cells/well in low glucose RPMI-1640 medium with $10 \%$ FBS, and were cultured for $24 \mathrm{~h}$. After washing the cells with PBS, fresh medium with $10 \%$ FBS was added. The QUE/TMZ-NLs, QUE/TMZ-FITC-NLs and free drugs were added to the cells at a final drug concentration of $0.25 \mu \mathrm{g} / \mathrm{ml}$ and incubated at $37^{\circ} \mathrm{C}$, in $5 \% \mathrm{CO}_{2}$ and $99 \%$ humidity for $4 \mathrm{~h}$. Prior to imaging, the cell culture medium was removed and the cells were washed twice with cold PBS and fixed using BD Cytofix/ Cytoperm $^{\text {TM }}$ (BD Biosciences, Franklin Lakes, NJ, USA) at $4^{\circ} \mathrm{C}$ for $10 \mathrm{~min}$. The samples were then mounted using Vecta Shield mounting medium containing DAPI (Vector Laboratories, Inc., (Burlingame, CA, USA) to label the nucleus. Images of the cellular uptake of the QUE/TMZ-NLs, free QUE or TMZ were captured using an Olympus FV1000 IX2 inverted confocal microscope with a 40x1.30 NA Olympus objective and FV10-ASW imaging software (Olympus Corp., Tokyo, Japan).

Cell viability assay. Cell viability was evaluated by 3-(4,5-dimethylthiazol-2-yl)-2,5-diphenyltetrazolium bromide (MTT) assay, as previously described $(20,21)$. The U87 glioma cells were seeded into a 96-well microplate at a density of $10^{5}$ cells/well. At $60-70 \%$ confluence, the cells were treated with the indicated concentrations of the QUE/TMZ-NLs, QUE-NLs, free TMZ, or control liposomes for $12 \mathrm{~h}$, and then allowed to grow in drug-free medium for $24 \mathrm{~h}$ prior to the measurement of the cytotoxicity. The kinetics of cell death were detected at 12, 24 and $48 \mathrm{~h}$ following treatment with 25 ,
50 and $100 \mu \mathrm{M}$ of QUE/TMZ-NLs, QUE-NLs, free TMZ, or control liposomes. The cells were then washed once with PBS, and incubated with fresh, complete RPMI-1640 medium (100 $\mu \mathrm{l} /$ well). MTT solution $(25 \mu \mathrm{l}$ of $2 \mathrm{mg} / \mathrm{ml}$ ) was added to each well. Following incubation at $37^{\circ} \mathrm{C}$ for $4 \mathrm{~h}$, the medium was removed by careful aspiration. In order to determine the number of viable cells, the optical density (OD) of each well was analyzed using an enzyme-linked immunosorbent assay (ELISA) plate reader ( $\mu$ Quat, KC-Junior program; Bio-Tec, Winooski, VT, USA) at a wavelength of $570 \mathrm{~nm}$. The percentage of viable cells relative to the control was obtained by dividing the average OD of the treated wells by the OD of the control wells as follows: cell viability rate $(\%)=\mathrm{OD}$ value of treated group/OD value of control group $x 100$; growth inhibition rate $(\%)=(1-$ OD value of treated group/OD value of control group) $\mathrm{x} 100$.

Apoptosis assay. Apoptosis was measured by Annexin V/ PI staining followed by flow cytometric analysis, as previously described $(22,23)$. The cells were incubated with various concentrations $(25,50,100$ and $200 \mu \mathrm{M})$ of the QUE/ TMZ-NLs, QUE-NLs or free TMZ for 12, 24, 36 and $48 \mathrm{~h}$. The cells were then trypsinized and harvested by centrifugation at 3,000 rpm for $5 \mathrm{~min}$, and incubated with Annexin V and PI for $15 \mathrm{~min}$ at room temperature prior to flow cytometric analysis.

Generation of a TMZ-resistant U87 (U87/TR) human glioma cell line. TMZ resistance was induced in the U87 cells step by step to produce the U87/TR cell line. Briefly, the U87 cells were cultured in RPMI-1640 medium supplemented with $10 \% \mathrm{FBS}$, and incubated in $5 \% \mathrm{CO}_{2}$ at $37^{\circ} \mathrm{C}$. The parental U87 cells were then incubated with incremental induction doses of TMZ (4.0-20.0 mM). After 14 days, the TMZ concentration was increased $(40,80,160$ and $320.0 \mathrm{mM})$ in the cell culture to establish the U87/TR cells. The U87/TR cells were incubated with $320.0 \mathrm{mM}$ TMZ for 7 days/month for 6 months to maintain stable drug resistance. The drug resistance was assayed by colony formation assay, as previously described $(24,25)$. The drug resistance index was determined based on the cytotoxicity of TMZ to the U87/TR cells and the parental U87 cells and measured by MTT assay.

Lactate dehydrogenase $(\mathrm{LDH})$ release assay for the determination of cell death. The U87/TR cells in 96-well plates were treated with free QUE, QUE/TMZ-NLs, QUE-NLs, free TMZ, control liposomes or dimethyl sulfoxide (DMSO) at 6.25, 12.5, $25,50,100$ and $200 \mu \mathrm{M}$ in triplicate wells. Following $24 \mathrm{~h}$ of incubation, the LDH levels in the supernatant were measured using an automatic biochemical analyzer (Hitachi 7060, Hitachi Koki Co. Ltd., Hitachinaka, Japan).

Biodistribution assay. After obtaining institutional approval from the Hubei Medical University Animal Care Committee, Sprague-Dawley (SD) rats $(\mathrm{n}=108,200-220 \mathrm{~g}, 10$ weeks old) were randomized for this blinded, placebo-controlled trial. All animals were handled with care and were allowed free access to water and food.

For biodistribution and plasma concentration assays, a stereodirected instrument was used to establish the in situ, in vivo model of glioblastoma by inoculating the U87 cells into the 
cerebral cortex of the SD rats. Briefly, the animals were anesthetized by an intraperitoneal injection of xylazine $(100 \mathrm{mg} / \mathrm{kg}$ body weight) and ketamine (10 mg/kg body weight) (Phoenix Pharmaceuticals Inc., Burlingame, CA, USA), and Lacri-Lube (Allergan Inc.) was applied across the cornea of the eyes. A burr hole was drilled in the skull $0.1 \mathrm{~mm}$ posterior to the bregma and $2.3 \mathrm{~mm}$ lateral to the midline. Live cells $\left(5 \times 10^{3}\right.$ in $2 \mu \mathrm{l}$ of PBS) were administered stereotactically (Stoelting Apparatus), into the burr hole, using a Hamilton syringe with a 32-gauge needle. The needle was advanced to a depth of $2.3 \mathrm{~mm}$ from the brain surface and the cell suspension delivered slowly over the course of 2-3 min. Following the injection, the needle was left in place for $2 \mathrm{~min}$, after which time, it was raised to a depth of $1.5 \mathrm{~mm}$ below the brain surface and left in place for an additional $1 \mathrm{~min}$. Upon withdrawal of the needle, the burr hole was sealed with bone wax and the incision sutured. The animals were randomly assigned into the control and treatment groups. The animals were weighed daily and humanely sacrificed by cervical dislocation when weight loss occurred ( $>10 \%$ of body weight) or until tumors were evident, whichever occurred first. The rats in the treatment groups were administered intragastrically with the indicated drugs at $25 \mathrm{mg} / \mathrm{kg}$ body weight beginning on day 7 after tumor development. The control animals received equivalent doses of control nanoliposomes.

The SD rats in the treatment groups were randomly divided into the single-dose or double-dose groups (QUE/ TMZ-NLs, QUE and TMZ group, n=18/group). At the same time point, the rats in the QUE group and TMZ group were treated with an intragastric administration $(25 \mathrm{mg} / \mathrm{kg}$ body weight) of QUE or TMZ, respectively, and the rats in the QUE/ TMZ-NLs group were treated with an intragastric administration $(25 \mathrm{mg} / \mathrm{kg}$ body weight) of QUE and TMZ (1:1). For the first administration, the rats received a single $25 \mathrm{mg} / \mathrm{kg}$ dose of QUE/TMZ-NLs (once per day). For the repeated administration, after the first administration $(12 \mathrm{~h})$, the rats received repeated doses of QUE/TMZ-NLs (twice per day). Following administration, the animals were housed in cages that allowed for free movements and natural postural positions. All the animals were given free access to food and water. From each group, 3 animals were euthanized by an intravenous injection of pentobarbital $(100 \mathrm{mg} / \mathrm{kg}$ body weight) at $30 \mathrm{~min}$ of treatment and terminal blood samples were collected at different time points $(2,4,8,12,24$ and $48 \mathrm{~h})$. The brain, liver, heart, kidneys, lungs and spleen were also harvested and placed into pre-weighed scintillation vials. The organ samples were homogenized. QUE in the tissue homogenate was subsequently extracted by methanol/HCl $(6: 4, \mathrm{v} / \mathrm{v})$, and analyzed by HPLC. For plasma drug concentration analysis, $400 \mu \mathrm{l}$ plasma samples were mixed with $1.0 \mathrm{ml}$ methanol/ $\mathrm{HCl}(6: 4, \mathrm{v} / \mathrm{v})$. Following incubation at $90^{\circ} \mathrm{C}$ for $5 \mathrm{~h}, 1.0 \mathrm{ml}$ ethyl acetate was added and the samples were centrifuged at $5,000 \mathrm{x} \mathrm{g}$ at $4^{\circ} \mathrm{C}$ for $10 \mathrm{~min}$. The supernatant was dried and reconstituted in $500 \mu \mathrm{l}$ methanol for HPLC analysis. The QUE or TMZ content in the samples was measured at 254 and $329 \mathrm{~nm}$, respectively. A Diamond C18 column was used with a flow rate of $1.0 \mathrm{ml} / \mathrm{min}$ for the eluent [methanol/0.5\% acetic acid (10:90)] for 0-19 $\mathrm{min}$.

Effects of repeated administration. The rats with glioma were used to assess the effects of the repeated administration of the QUE/TMZ-NLs $(25 \mathrm{mg} / \mathrm{kg})$ on the plasma drug concentration.
At $0.5,1,2,4,8,12,24$ and $48 \mathrm{~h}$ following administration, blood samples were collected from the eyes of 6 rats in each group, and centrifuged at 5,000 $\mathrm{x} g$ for $10 \mathrm{~min}$ to obtain plasma. The plasma drug concentrations were determined by HPLC, as described above.

Statistical analysis. Data are represented as the means \pm standard deviation (SD) and were analyzed by two-tailed Student's t-tests using the Statistical Program for Social Sciences (SPSS) 13.0 software (SPSS Corp., Shanghai, China). A p-value of $<0.05$ was considered to indicate a statistically significant difference.

\section{Results}

Preparation and characterization of QUE/TMZ-NLs. The size distribution of the QUE/TMZ-NLs was in the range of 100 to $300 \mathrm{~nm}$, and the size distribution of the QUE-NLs ranged from 50 to $200 \mathrm{~nm}$, as measured by a laser particle analyzer (Fig. 1A). Transmission electron microscopy (TEM) analysis revealed that the QUE/TMZ-NLs formed spherical particles with a small diameter and a narrow size distribution compared to the QUE-NLs (Fig. 1B).

UV-VIS spectroscopy revealed similar spectra of the QUE/TMZ-NLs and QUE-NLs, indicating that, as expected, the core of the QUE/TMZ-NLs remained unaltered following the addition of TMZ (Fig. 1C), compared to that of the QUE-NLs, which was measured by the absorbance readings of the liposome cores. HPLC spectroscopy further revealed that the ratio of QUE/TMZ remained almost unaltered following the attachment of DSPE-PEG2000 (Fig. 1D). The schematic illustration in Fig.1E presents the possible packing arrangement of the PEGylated-coated QUE/TMZ0-NLs consisting of an aqueous bilayer and a lipid core. The hydrophobic components in the aqueous bilayer and QUE and TMZ were located in the middle of the lipid core.

To further examine the drug/carrier interaction, we analyzed the FTIR spectra of QUE, QUE-NLs, TMZ and QUE/ TMZ-NLs. The characteristic peaks associated with specific structural features of the drug molecules were observed in QUE, QUE-NLs, TMZ and QUE/TMZ-NLs (Fig. 2), indicating that there was no substantial chemical interaction between the drugs and the carriers. The lack of drug/carrier interaction was possibly due to the high EE of QUE/TMZ in the nanoparticles in the presence of ATO and the overlapping with the -NH groups in QUE/TMZ. In addition, there were a large number of functional groups in QUE and TMZ, providing possible masking effects on the infrared peaks, which were otherwise visible.

EE and drug loading. The loading content and the EE of QUE or TMZ in the NLs were calculated (Table I). The EE of QUE in the QUE/TMZ-NLs varied in the range of 69.42 to $78.37 \%$. The EE of TMZ ranged from 53.58 to $66.25 \%$. Compared with the EE of the QUE-NLs (85.72\%), the addition of TMZ had no significant effect on the EE of QUE in the liposomes.

In vitro drug release profiles and uptake of the QUE/TMZ-NLs by human U87 glioma cells. The release profile of QUE and $\mathrm{TMZ}$ from the QUE/TMZ-NLs revealed sustained drug release 
A
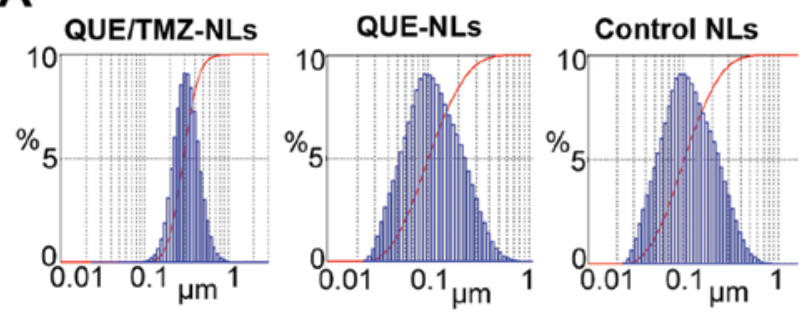

B


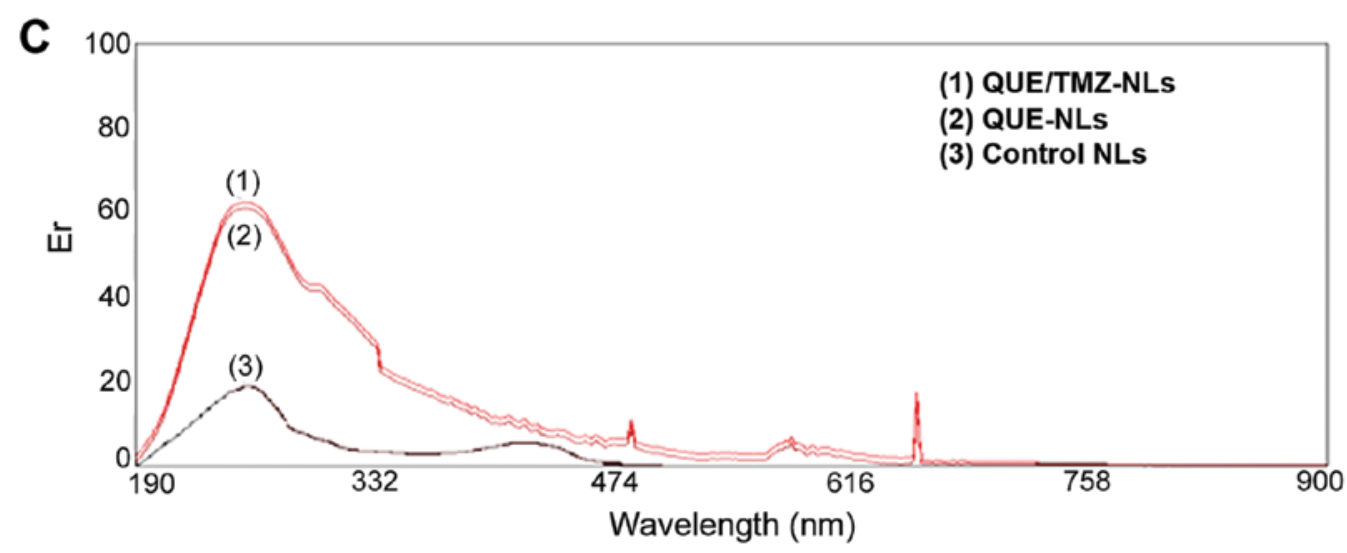

D

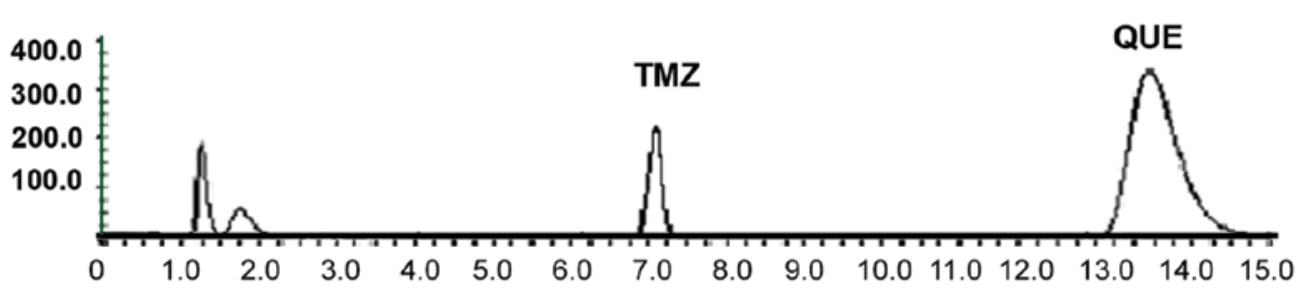

E<smiles>O=c1c(O)c(-c2ccc(O)c(O)c2)oc2cc(O)cc(O)c12</smiles>

Quercetin (QUE)

Tween 80

Poloxamer 188

DSPE-PEG2000<smiles>Cn1nnc2c(C(N)=O)ncn2c1=O</smiles>

Glyceryl behenate (ATO) Cholesterol

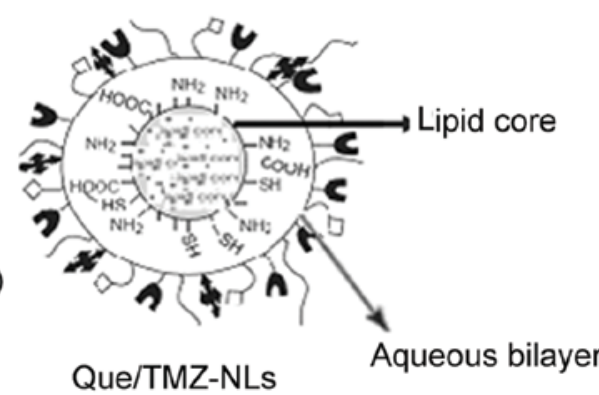

Temozolomide (TMZ)

Figure 1. Characterization of the quercetin and temozolomide-loaded nanoliposomes (QUE/TMZ-NLs). (A) A laser particle analyzer was used to examine the size distribution of the QUE/TMZ-NLs, QUE-NLs, and control NLs, the average diameters of which were 196.5 $\pm 47.3,134.5 \pm 42.2$ and $106.8 \pm 37.6 \mathrm{~nm}$, respectively. (B) Representative TEM images of the QUE-TMZ-NLs, QUE-NLs and the control NLs. (C) The UV-VIS spectra show similar traces for the QUE/ TMZ-NLs, QUE-NLs and the control NLs, indicating that their cores were identical. (D) Stacked HPLC traces of QUE and TMZ. (E) Schematic illustration of the possible packing arrangement of the PEGylated-coated QUE/TMZ-NLs consisting of an aqueous bilayer and a lipid core. QUE, quercetin; TMZ, temozolomide; NLs, nanoliposomes; TEM, transmission electron microscope.

at $37^{\circ} \mathrm{C}$ (Fig. 3A). Within $12 \mathrm{~h}, 90 \%$ of QUE was released from the QUE/TMZ-NLs, whereas approximately $75 \%$ of TMZ was released. Approximately $90 \%$ of TMZ was released from the QUE/TMZ-NLs after $24 \mathrm{~h}$. 
Table I. The loading content, EE, particle size, PI and $\zeta$-potential of lipid formulations of QUE/TMZ.

\begin{tabular}{|c|c|c|c|c|c|}
\hline Lipid formulations & Size (nm) & PI & $\zeta$-potential & Loading content (\%) & $\mathrm{EE}(\%)$ \\
\hline QUE-NLs & $134.6 \pm 62.2$ & $0.26 \pm 0.06$ & $21.8 \pm 5.4$ & $26.23 \pm 2.34$ & $85.72 \pm 9.34$ \\
\hline QUE/TMZ-NLs & $196.5 \pm 47.3$ & $0.32 \pm 0.09$ & $30.5 \pm 6.9$ & - & - \\
\hline QUE/TMZ-NLs (QUE) & - & - & - & $23.42 \pm 2.17$ & $69.42-78.37$ \\
\hline QUE/TMZ-NLs (TMZ) & - & - & - & $15.87 \pm 1.96$ & $53.58-66.25$ \\
\hline Control liposomes & $106.8 \pm 37.6$ & $0.17 \pm 0.04$ & $16.6 \pm 3.8$ & - & - \\
\hline
\end{tabular}

Data represent the means \pm SD of 3 separate experiments $(n=3)$. EE, entrapment efficiency; QUE, quercetin; TMZ, temozolomide; PI, propidium iodide; NL, nanoliposome.


Figure 2. FTIR spectra of QUE, QUE-NLs, TMZ and quercetin and temozolomide-loaded nanoliposomes (QUE/TMZ-NLs). The presence of characteristic peaks associated with specific structural characteristics of the drug molecule are observed in the raw materials of (A) QUE, (B) QUE-NLs, (C) TMZ and (D) QUE/TMZ-NLs. FTIR, Fourier transform infrared spectroscopy; QUE, quercetin; TMZ, temozolomide; NLs, nanoliposomes. 

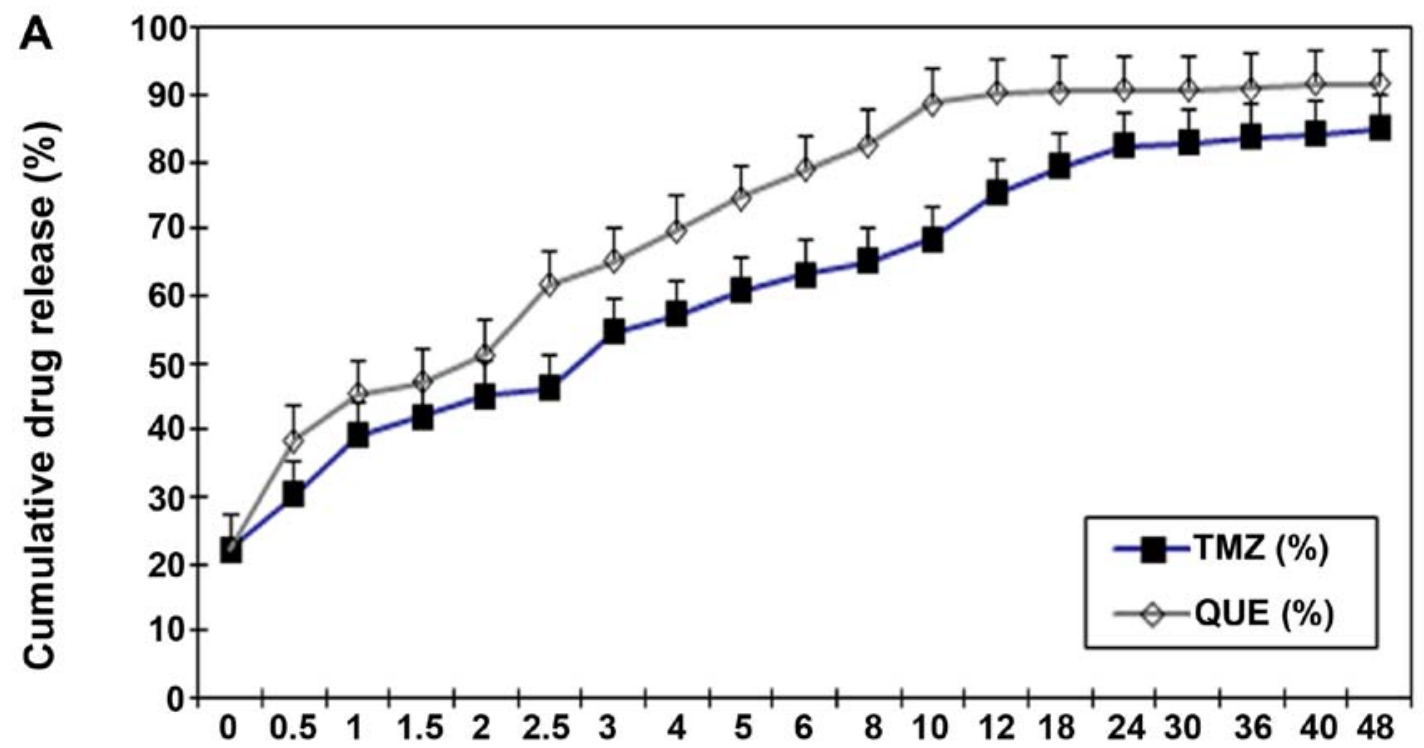

\section{Time (h)}

\section{B QUE/TMZ-NLs}

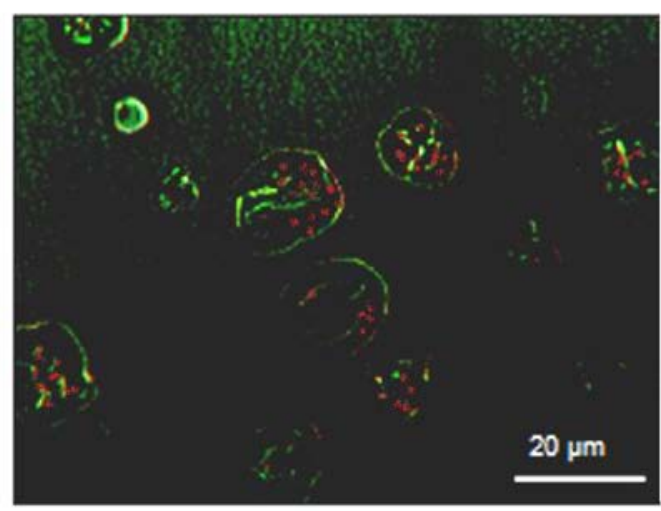

\section{Free drugs}

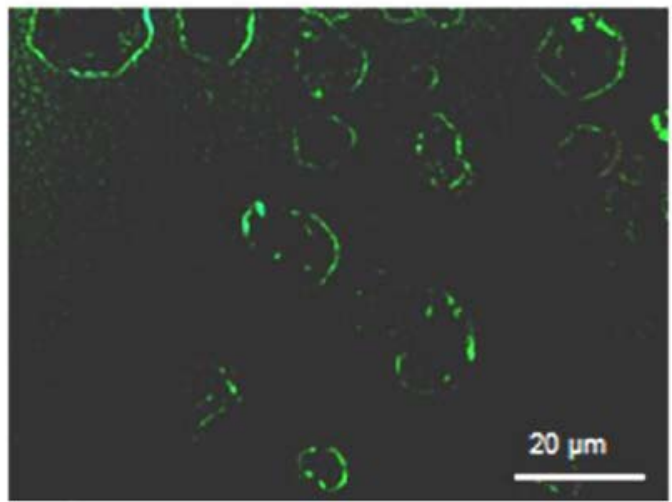

Figure 3. In vitro drug release profile and cellular uptake of the quercetin and temozolomide-loaded nanoliposomes (QUE/TMZ-NLs). (A) The release of TMZ and QUE from the QUE/TMZ-NLs were monitored within a time frame of $48 \mathrm{~h}$. Data are shown as the means \pm SD (n=3). (B) Comparison of the uptake of the QUE/TMZ-FITC-NLs and free drugs by U87 human glioma cells was determined. Representative images taken by confocal microscopy are shown. Red, QUE or TMZ; green, cell nuclei. Scale bar, $20 \mu \mathrm{m}$. QUE, quercetin; TMZ, temozolomide; NLs, nanoliposomes.

We further examined the uptake of the QUE/TMZ-NLs by the U87 cells. The QUE/TMZ-FITC-NLs were incubated with the U87 cells and the internalization of the QUE/TMZ-FITC-NLs was analyzed using confocal fluorescence microscopy. The uptake of free QUE or TMZ dissolved in DMSO was compared at the same concentrations. The uptake of the QUE/TMZ-NLs in the cytoplasm appeared diffuse rather than punctate (Fig. 3B), suggesting that the internalized drugs in the QUE/TMZ-NLs had escaped from the endosomes. By contrast, the uptake of the free drugs was substantially lower, due to the limited solubility of QUE and TMZ in the cell culture media.

QUE/TMZ-NLs exerts cytotoxic effects on the U87 glioma cells in vitro. As shown by MTT assay, the QUE/TMZ-NLs significantly decreased the viability of the U87 cells compared with free TMZ or the QUE-NLs (Fig. 4A). While free TMZ did not show any noticeable cytotoxicity towards the U87 glioma cells at the concentrations tested and the QUE-NLs caused only limited cytotoxicity, the QUE/TMZ-NLs induced significant cell death at the same concentrations, inducing a 1.5 -fold increase in cytotoxicity compared with QUE at 25-100 $\mu \mathrm{M}$ and a 1.8-fold increase in cytotoxicity compared with free TMZ. In addition, the QUE/TMZ-NLs induced marked morphological changes and cell death (apoptotic cells were characterized by condensed or fragmented nuclei) at $100 \mu \mathrm{M}$ following $24 \mathrm{~h}$ of incubation with the U87 cells (Fig. 4B), whereas QUE or TMZ alone had minimal effects on cell morphology. We further demonstrated that the QUE/TMZ-NL-induced cell death was due to apoptosis. The percentage of the Annexin $\mathrm{V}^{+}$cells markedly increased, and the effects of the QUE/TMZ-NLs were more prominent than those of QUE or TMZ alone, while the percentage of $\mathrm{PI}^{-}$cells was very low (Fig. 4C); these effects occurred in a time- and dose-dependent manner (Fig. 4D).

QUE/TMZ-NLs exert cytotoxic effects on the TMZ-resistant U87/TR cells in vitro. Drug resistance is a major issue in the treatment of brain tumors (26). Thus, in the present study, we 


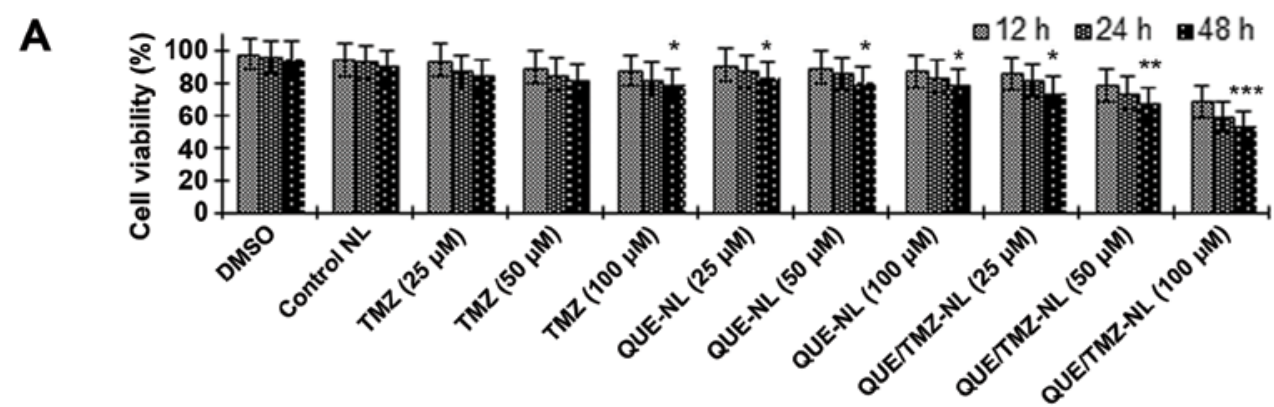

B QUE/TMZ-NLS:
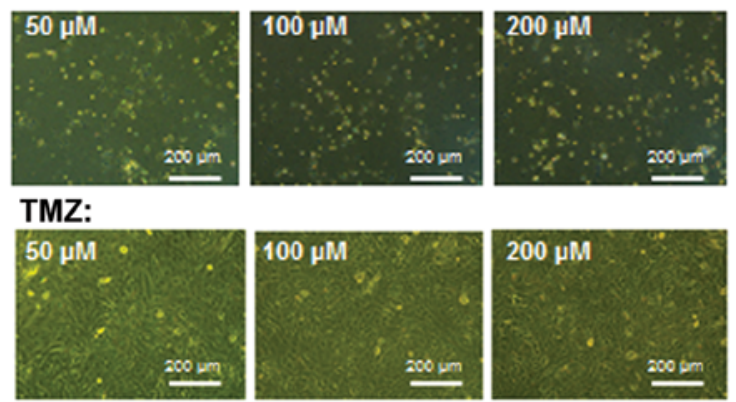

QUE-NLs:
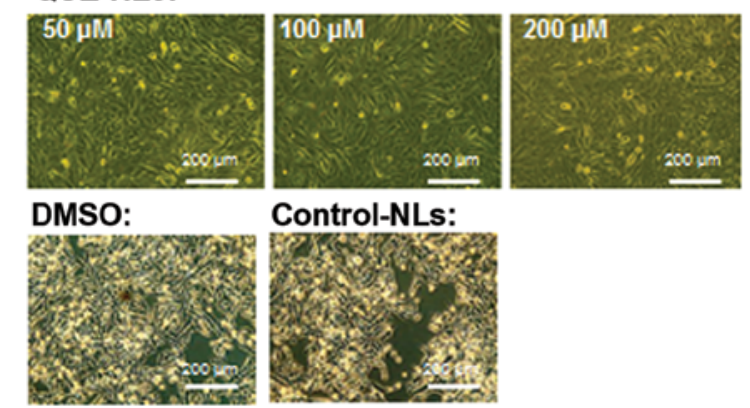

QUE-NLs:

C QUE/TMZ-NLs:

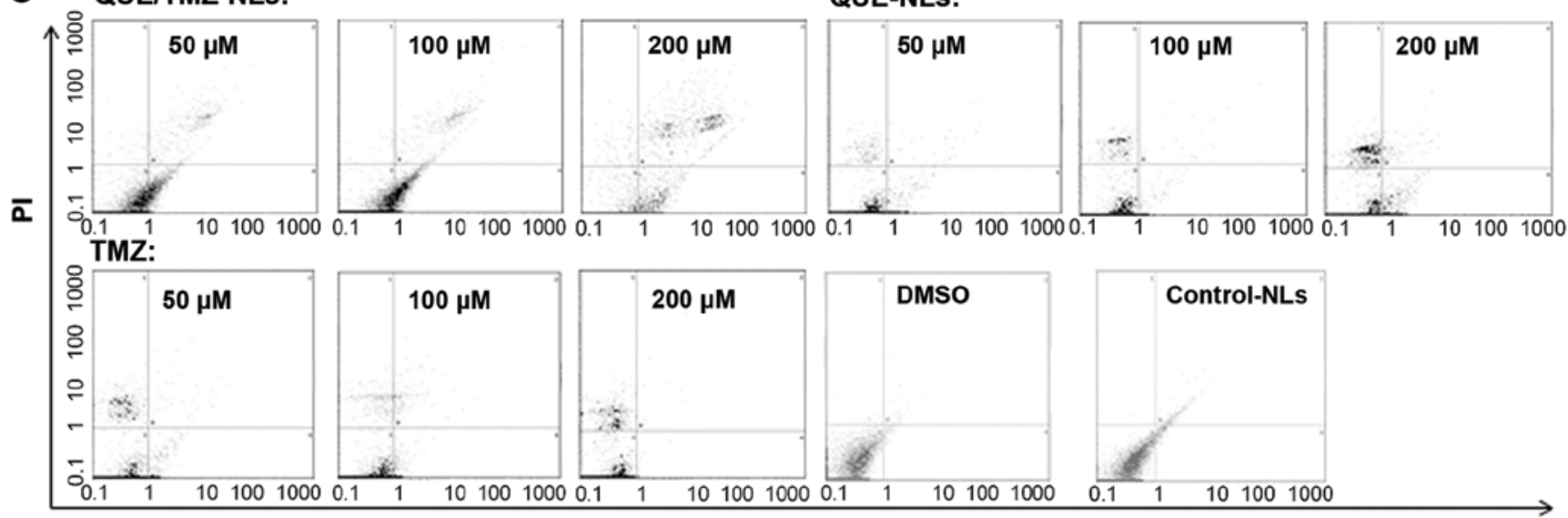

Annexin V-FITC

D

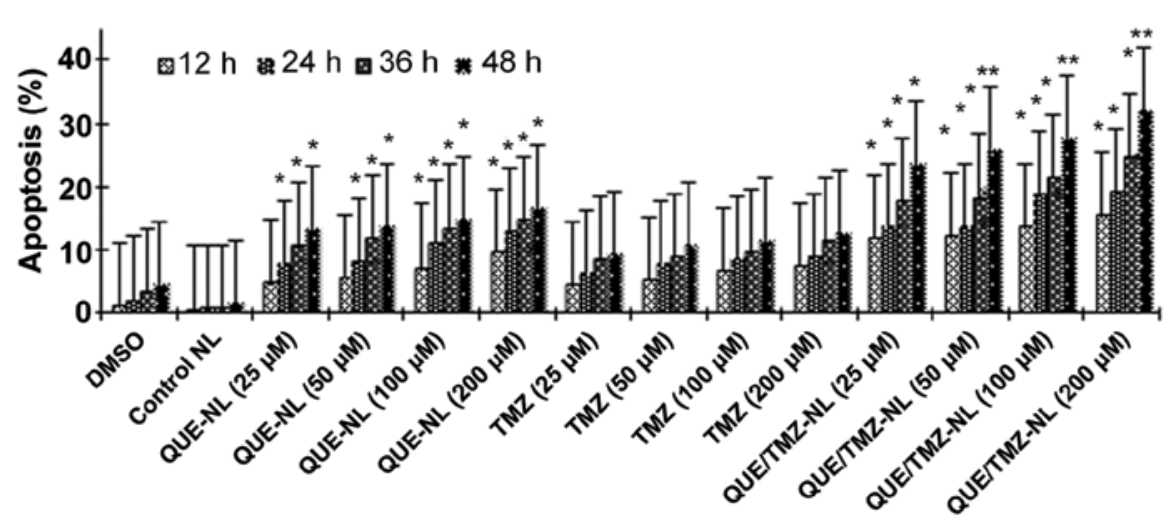

Figure 4. Quercetin and temozolomide-loaded nanoliposomes (QUE/TMZ-NLs) exert cytotoxic effects on the U87 glioma cells. (A) Treatment with QUE/ TMZ-NL decreased U87 cell viability. Each point is the mean \pm SD of 3 experiments. (B) Cell morphology was examined using a phase contrast microscope. Representative images of the indicated treatments are shown. (C and D) QUE/TMZ-NLs induced the apoptosis of the U87 cells, as measured by Annexin V-FITC/PI staining and flow cytometry. The cells were cultured with the indicated concentrations of QUE/TMZ-NLs, free QUE or TMZ for 12, 24, 36 and $48 \mathrm{~h}$. Each point is the mean \pm SD of 3 experiments. ${ }^{*} \mathrm{p}<0.05,{ }^{* *} \mathrm{p}<0.01$ and $^{* * * *} \mathrm{p}<0.001$ compared with the control. QUE, quercetin; TMZ, temozolomide; NLs, nanoliposomes; PI, propidium iodide. 



Figure 5. Quercetin and temozolomide-loaded nanoliposomes (QUE/TMZ-NLs) exert cytotoxic effects on the temozolomide-resistant U87 glioma cells (U87/ TR cells). (A) The relative colony formation rate of the U87/TR cells following treatment with TMZ at the indicated concentrations. (B) The effects of TMZ on the viability of U87 and U87/TR cells. (C) Cell death was measured by the release of LDH from the U87/TR cells. (D) Treatment with QUE/TMZ-NLs decreased the viability of the U87/TR glioma cells as measured by MTT Assay. ${ }^{*} \mathrm{p}<0.05,{ }^{* *} \mathrm{p}<0.01$ and ${ }^{* * *} \mathrm{p}<0.001$ compared with the control. QUE, quercetin; TMZ, temozolomide; NLs, nanoliposomes.

established a TMZ-resistant brain tumor cell line, U87/TR, in order to examine the cytotoxic effects of the QUE/TMZ-NLs. Compared with the parental U87 cells, the U87/TR cells had a significantly better ability in forming colonies in the presence of TMZ ( $<<0.05)$, with resistance indexes in a range of 1.5-8.0 at different TMZ concentrations (Fig. 5A). As shown by MTT assay, the IC50 value of TMZ was $9.24 \mathrm{mM}$ in the U87 cells, and was $38.65 \mathrm{mM}$ in the U87/TR cells, with a resistance index of 4.18 (Fig. 5B).

Cell death was further assessed by measuring the release of LDH from the U87/TR cells treated with or without the QUE/TMZ-NLs. The QUE/TMZ-NLs significantly upregulated the release of LDH by the U87/TR cells ( $p<0.01)$, compared with the control NLs and the DMSO control. TMZ alone had 
no significant effect on the release of LDH by the U87/TR cells (Fig. 5C). These results indicate that the QUE/TMZ-NLs have superior anticancer effects on TMZ-resistant glioma cells.

In addition, the OD value, measured by MTT assay, which indicates the number of viable cells, was significantly decreased by the QUE/TMZ-NLs in a time- and dose-dependent manner. Compared with the same concentrations of QUE or TMZ, treatment with the QUE/TMZ-NLs resulted in significantly lower OD values (Fig. 5D).

Biodistribution of the QUE/TMZ-NLs in vivo. To determine the biodistribution of the QUE/TMZ-NLs, QUE-NLs and free TMZ in rats with in situ glioma, we administered these NLs or free drugs intragastrically, and collected brain, liver, heart, kidney, spleen and lung samples after 2, 4, 8, 12, 24 or $48 \mathrm{~h}$ for HPLC analysis (Fig. 6A). Compared with the QUE-NLs or free TMZ, the QUE/TMZ-NLs significantly accumulated in the brain, indicating that the QUE/TMZ-NLs would achieve improved therapeutic efficacy and potency for the treatment of glioma. Free TMZ and the QUE-NLs were accumulated in the kidneys and heart. The QUE-NLs and the QUE/TMZ-NLs were accumulated in the liver, but the content of QUE/TMZ-NLs in the brain was higher than that in the liver.

The plasma concentrations of the QUE/TMZ-NLs, free QUE and TMZ were determined after they were administered to the glioma-bearing rats (Fig. 6B). In the form of QUE/ TMZ-NLs, both QUE and TMZ exhibited higher plasma concentrations compared with the free drugs. The drug clearance of QUE/TMZ-NLs was also delayed. As regards the accelerated blood clearance (ABC) phenomenon with the conventional DSPE-PEG2000 modified liposomes (27-29), we further compared the plasma clearance rates of single and dual administrations. There was a slight increase in the plasma clearance rate following the repeated administration of the QUE/TMZ-NLs (Fig. 6C), whereas the plasma concentration of TMZ administered as a free drug did not significantly decrease after repeated administrations.

\section{Discussion}

Nanotechnology used in conjunction with existing therapies has been shown to improve the reversal of drug resistance. The related mechanisms include specific drug targeting, enhanced cellular uptake and improved bioavailability of drugs with poor physicochemical characteristics $(30,31)$. Multidrug resistance is a common issue that has been linked with the failure of chemotherapy for brain tumors. To overcome drug resistance, multiple brain tumor-targeted drug delivery systems have been developed with decreased off-target toxicity and improved pharmacokinetics/harmacodynamics compared with conventional formulations (32). Lipid nanoparticles, such as solid NLs and nanostructured lipid carriers (NLCs), have been shown to provide a favorable means for efficient drug delivery to tumor sites, while minimizing their side-effects $(33,34)$. In this study, we loaded QUE and TMZ into a PEGylated liposomal carrier, characterized its physicochemical and pharmacokinetic properties, and the antitumor potency in vitro and in vivo.

Recently, anticancer drugs with methylating properties, including TMZ, have been investigated, particularly for the therapy of malignant glioblastomas (35). Although TMZ can be administered orally and pass the blood brain barrier, its half-life is $<2 \mathrm{~h}$ and thus, it does not reach the tumor site at effective therapeutic concentrations. In addition, the off-target toxicities of TMZ, such as neurotoxicity and reproductive toxicity, further limit its therapeutic efficacy in the treatment of glioma.

QUE has been identified as a potential agent for cancer prevention due to its ability to suppress cancer initiation and promote programmed cell death (36). QUE is also a free radicalscavenging antioxidant owing to the abundancy of hydroxyl groups and conjugated $\mathrm{p}$ orbitals which donate either electrons or hydrogen, and scavenge $\mathrm{H}_{2} \mathrm{O}_{2}$ and superoxide anion (14). It has been reported that in low glutathione (GSH) environments, oxidized QUE reacts with thiol groups in proteins, exerting cytotoxicity towards cells $(37,38)$. On the other hand, long-term exposure to high concentrations of QUE has been demonstrated to decrease the GSH content, suggesting the inability of QUE to decrease reactive oxygen species (ROS) production for that period. As a consequence, the pro-oxidant effect of QUE may prevail over its antioxidant effect, thus resulting in cell death by damaging the cellular compartments (39).

Recent findings have increased our understanding of the pharmacological mechanisms of TMZ (40). One mechanism through which TMZ exerts cytotoxic effects through its inhibitory effect on phosphoinositide 3-kinase (PI3K), which is often overexpressed and activated in glioblastoma. It was previoulsy reported that a PI3K inhibitor sensitized glioblastoma cells to TMZ-induced apoptosis in vitro through an unknown mechanism $(41,42)$. In addition, QUE has been shown to inhibit the activity of PI3K, suggesting that the inhibition of PI3K is one of the mechanisms through which QUE enhances the therapeutic efficiency of TMZ (43). Further studies on drugs that enhance the potency of TMZ without significant off-target toxicity are warranted, and this would help to improve the therapeutic benefits and prolong survival.

The biodistribution and the antitumor activity of the QUE/TMZ-NLs were evaluated in the present study. Of note, the QUE/TMZ-NLs were not only more soluble in water and prolonged the circulation times of QUE in the blood, but also exerted enhanced antitumor effects by killing both drugsensitive and drug-resistant glioma cells, which was possibly due to the high intracellular drug concentration. Other studies have also demonstrated that loading hydrophobic anticancer agents into polymersomes has the potential to reduce their systemic toxicity and enhance their antitumor effects in animal models (44-46). Phospholipid NLs represent a classic example of fully degradable drug delivery systems (47-49). PEG coating has been developed to improve the circulation properties of carriers in the bloodstream. For example, a previous study demonstrated that the PEGylation of liposomes increases their half-life from $<30 \mathrm{~min}$ to approximately $5 \mathrm{~h}$ in mice (50). Other benefits have also been found. For example, due to their dense PEG surface brush, polymersomes and filomicelles are compatible with blood (51), as they: i) remain suspended and flexible in the plasma; ii) do not adhere to red blood cells and leukocytes in the blood; iii) do not fix opsonins or activate complement; and iv) do not cause hemolysis.

In the present study, a slight $\mathrm{ABC}$ phenomenon was observed when repeated administrations of the QUE/TMZ-NLs were administered to the rats. The ABC phenomenon is important 

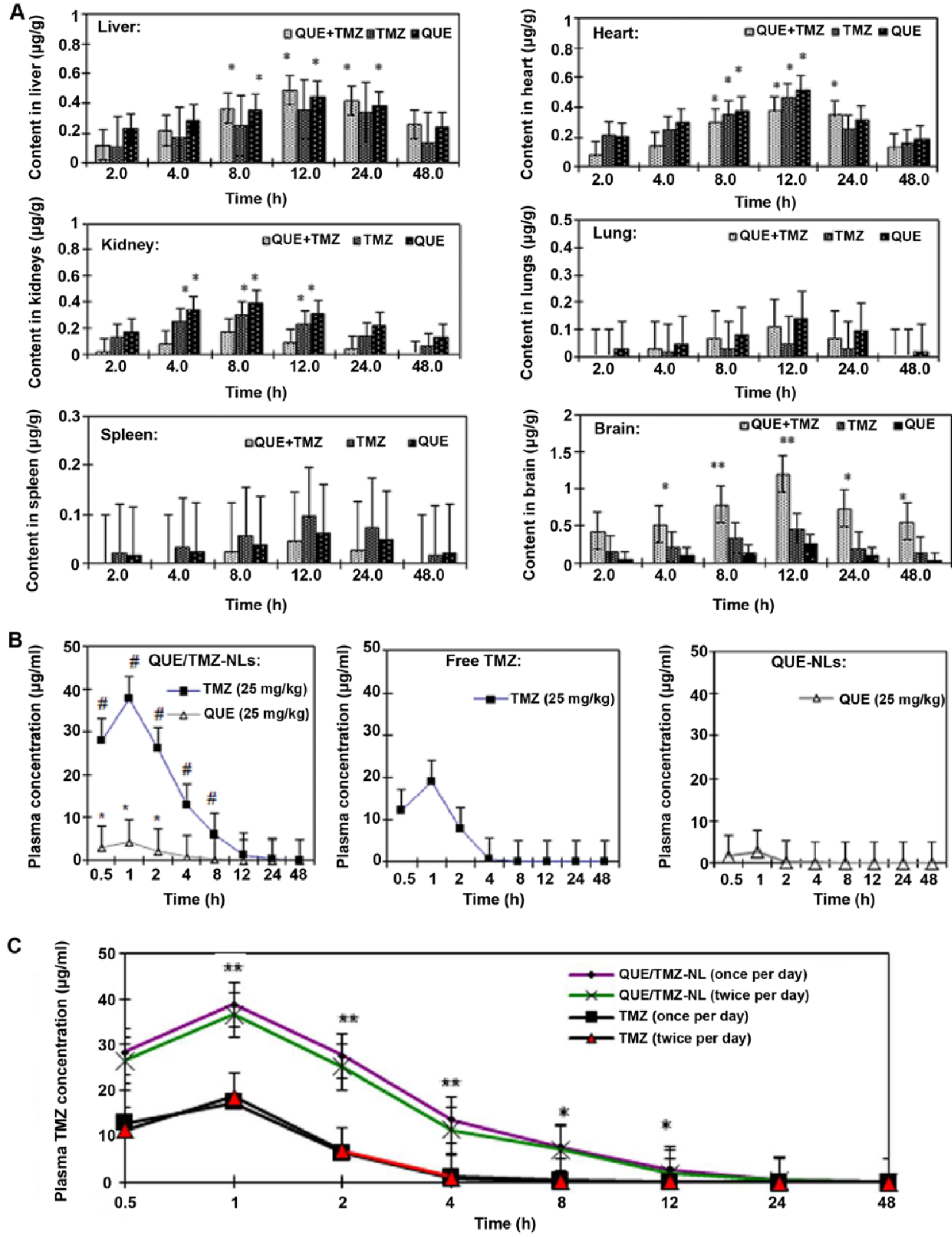

Figure 6. Biodistribution and clearance of the quercetin and temozolomide-loaded nanoliposomes (QUE/TMZ-NLs) compared with the QUE-NLs or free TMZ (A) The biodistribution of QUE and TMZ in the QUE/TMZ-NL, QUE-NLs and free TMZ in the brain, liver, heart, kidneys, lungs and spleen of glioma-bearing rats. The y-axis in all images was normalized to the total content of QUE and TMZ divided by the weight of the organ. This value is then divided by the initial QUE or TMZ content administered in each rat. ANOVA analysis showed statistical significance ( ${ }^{*}<<0.05$ and ${ }^{* *}$ p $\left.<0.01\right)$ compared with the QUE-NLs and free TMZ. (B) Plasma drug concentrations were shown at the indicated time points after the administration of a single dose of TMZ at $25 \mathrm{mg} / \mathrm{kg}$, QUE-NLs at $25 \mathrm{mg} /$ $\mathrm{kg}$, and 2-in-1 QUE/TMZ-NL with QUE at $25 \mathrm{mg} / \mathrm{kg}$ and TMZ at $25 \mathrm{mg} / \mathrm{kg}$. ${ }^{*} \mathrm{p}<0.05$ for the TMZ concentration difference between free TMZ and 2-in-1 QUE/ TMZ-NLs. * $\mathrm{p}<0.05$ for the QUE concentration difference between QUE-NLs and QUE/TMZ-NLs (means \pm SEM, $\mathrm{n}=6$ ). (C) Blood clearance of QUE and TMZ in glioma-bearing rats after a single administration or dual administrations of QUE/TMZ-NLs. The plasma TMZ concentration decreased significantly at 1, 2 and $4 \mathrm{~h}$ after the repeated administration of QUE/TMZ-NLs. ANOVA revealed statistical significance $\left({ }^{*} \mathrm{p}<0.05\right.$ and $\left.{ }^{* *} \mathrm{p}<0.01\right)$ compared with the QUE-NLs and free TMZ. QUE, quercetin; TMZ, temozolomide; NLs, nanoliposomes. 
for the development of drug delivery systems, particularly in the case of repeated administrations of nanoparticles. Researchers have used different animal models, including rats, mice, rhesus monkeys and rabbit, to investigate the mechanism underlyingof the ABC phenomenon. Dams et al reported that rhesus monkeys and rats presented with the ABC phenomenon after repeated administrations of PEGylated liposomes, whereas mice did not (52). Ishida et al examined the liposomal characteristics that affected the ABC phenomenon and demonstrated that an intense accelerated clearance may be induced in mice (53). Although the observations of the ABC phenomenon from animal experiments and from clinical treatment may not be fully consistent, it is necessary to carefully examine the distribution in the body and the pharmacokinetics of the drugs when repeated administrations are required.

In conclusion, in this study, a novel liposomal formulation of QUE/TMZ-NLs was designed and evaluated. We demonstrated that NLs serve as an effective drug delivery platform, both in vitro and in vivo, when loaded with TMZ and QUE. Importantly, the QUE/TMZ liposomal formulation proved to be more effective at killing glioma cells than free TMZ or QUE. Biodistribution assays demonstrated that although the QUE/ TMZ-NLs reached the tissues, they primarily accumulated in the brain and the liver. The ABC phenomenon was induced by the prolonged administration of PEGylated liposomes to rats and was accompanied by a substantial increase in liver uptake. Taken together, these findings indicate that this formulation possesses characteristics, such as a high drug encapsulation ratio, a low in vitro release rate, slow drug clearance and prolonged circulation time in vivo.

\section{Acknowledgements}

The authors would like to thank Dr R.M. Li for providing the cell lines, the Hubei Provincial Key Laboratory of Embryo Stem Cells for providing the facilities for the experiments, Mr. Z.Q. Liu and Mr. J.B. Feng for their assistance with the flow cytometry experiments, and Dr D.S. Li for the helpful discussions regarding chemistry. This study was supported by funding from the project of the Hubei Provincial Education Department.

\section{References}

1. Allen TM and Cullis PR: Drug delivery systems: entering the mainstream. Science 303: 1818-1822, 2004.

2. Wang AZ, Gu F, Zhang L, Chan JM, Radovic-Moreno A, Shaikh MR and Farokhzad OC: Biofunctionalized targeted nanoparticles for therapeutic applications. Expert Opin Biol Ther 8: 1063-1070, 2008.

3. Zhang L, Gu FX, Chan JM, Wang AZ, Langer RS and Farokhzad OC: Nanoparticles in medicine: therapeutic applications and developments. Clin Pharmacol Ther 83: 761-769, 2008

4. Ji JL, Huang XF and Zhu HL: Curcumin and its formulations: potential anti-cancer agents. Anticancer Agents Med Chem 12: 210-218, 2012.

5. Yezhelyev MV, Gao X, Xing Y, Al-Hajj A, Nie S and O'Regan RM: Emerging use of nanoparticles in diagnosis and treatment of breast cancer. Lancet Oncol 7: 657-667, 2006.

6. Papahadjopoulos D, Allen TM, Gabizon A, Mayhew E, Matthay K, Huang SK, Lee KD, Woodle MC, Lasic DD and Redemann C: Sterically stabilized liposomes: improvements in pharmacokinetics and antitumor therapeutic efficacy. Proc Natl Acad Sci USA 88: 11460-11464, 1991.

7. Gabizon A and Martin F: Polyethylene glycol-coated (pegylated) liposomal doxorubicin. Rationale for use in solid tumours Drugs 54 (Suppl 4): 15-21, 1997.
8. Haran G, Cohen R, Bar LK and Barenholz Y: Transmembrane ammonium sulfate gradients in liposomes produce efficient and stable entrapment of amphipathic weak bases. Biochim Biophys Acta 1151: 201-215, 1993.

9. Gang W, Jie WJ, Ping ZL, Ming S, Ying LJ, Lei W and Fang Y: Liposomal quercetin: evaluating drug delivery in vitro and biodistribution in vivo. Expert Opin Drug Deliv 9: 599-613, 2012.

10. Wang G, Wang J, Luo J, Wang L, Chen X, Zhang L and Jiang S: PEG2000-DPSE-coated quercetin nanoparticles remarkably enhanced anticancer effects through induced programed cell death on C6 glioma cells. J Biomed Mater Res A 101: 3076-3085, 2013.

11. Xavier CP, Lima CF, Rohde M and Pereira-Wilson C: Quercetin enhances 5-fluorouracil-induced apoptosis in MSI colorectal cancer cells through p53 modulation. Cancer Chemother Pharmacol 68: 1449-1457, 2011.

12. Siegelin MD, Reuss DE, Habel A, Rami A and von Deimling A: Quercetin promotes degradation of survivin and thereby enhances death-receptor-mediated apoptosis in glioma cells. Neuro-oncol 11: 122-131, 2009.

13. Kim EJ, Choi CH, Park JY, Kang SK and Kim YK: Underlying mechanism of quercetin-induced cell death in human glioma cells. Neurochem Res 33: 971-979, 2008.

14. Heijnen CG, Haenen GR, van Acker FA, van der Vijgh WJ and Bast A: Flavonoids as peroxynitrite scavengers: the role of the hydroxyl groups. Toxicol In Vitro 15: 3-6, 2001.

15. Ong CS, Tran E, Nguyen TT, Ong CK, Lee SK, Lee JJ, Ng CP, Leong $\mathrm{C}$ and Huynh $\mathrm{H}$ : Quercetin-induced growth inhibition and cell death in nasopharyngeal carcinoma cells are associated with increase in Bad and hypophosphorylated retinoblastoma expressions. Oncol Rep 11: 727-733, 2004.

16. Gupta K and Panda D: Perturbation of microtubule polymerization by quercetin through tubulin binding: a novel mechanism of its antiproliferative activity. Biochemistry 41: 13029-13038, 2002.

17. Wang IK, Lin-Shiau SY and Lin JK: Induction of apoptosis by apigenin and related flavonoids through cytochrome c release and activation of caspase- 9 and caspase-3 in leukaemia HL-60 cells. Eur J Cancer 35: 1517-1525, 1999.

18. Jakubowicz-Gil J, Langner E and Rzeski W: Kinetic studies of the effects of Temodal and quercetin on astrocytoma cells. Pharmacol Rep 63: 403-416, 2011.

19. Yang CY, Tsay SY and Tsiang RC: Encapsulating aspirin into a surfactant-free ethyl cellulose microsphere using non-toxic solvents by emulsion solvent-evaporation technique. J Microencapsul 18: 223-236, 2001.

20. Saha S, Reddy ChV, Xu S, Sankar S, Neamati N and Patro B: Synthesis and SAR studies of marine natural products ma'edamines A, B and their analogues. Bioorg Med Chem Lett 23: 5135-5139, 2013.

21. Zeng LF, Wang Y, Kazemi R, Xu S, Xu ZL, Sanchez TW, Yang LM, Debnath B, Odde S, Xie H, et al: Repositioning HIV-1 integrase inhibitors for cancer therapeutics: 1,6-naphthyridine7-carboxamide as a promising scaffold with drug-like properties. J Med Chem 55: 9492-9509, 2012.

22. Xu S, Oshima T, Imada T, Masuda M, Debnath B, Grande F, Garofalo A and Neamati N: Stabilization of MDA-7/IL-24 for colon cancer therapy. Cancer Lett 335: 421-430, 2013.

23. Xu S, Butkevich AN, Yamada R, Zhou Y, Debnath B, Duncan R, Zandi E, Petasis NA and Neamati N: Discovery of an orally active small-molecule irreversible inhibitor of protein disulfide isomerase for ovarian cancer treatment. Proc Natl Acad Sci USA 109: 16348-16353, 2012.

24. Yamada R, Kostova MB, Anchoori RK, Xu S, Neamati N and Khan SR: Biological evaluation of paclitaxel-peptide conjugates as a model for MMP2-targeted drug delivery. Cancer Biol Ther 9: 192-203, 2010.

25. Xu S, Grande F, Garofalo A and Neamati N: Discovery of a novel orally active small-molecule gp130 inhibitor for the treatment of ovarian cancer. Mol Cancer Ther 12: 937-949, 2013.

26. Thirant C, Gavard J, Junier MP and Chneiweiss H: Critical multiple angiogenic factors secreted by glioblastoma stem-like cells underline the need for combinatorial anti-angiogenic therapeutic strategies. Proteomics Clin Appl 7: 79-90, 2013.

27. Koide H, Asai T, Hatanaka K, Akai S, Ishii T, Kenjo E, Ishida T, Kiwada $\mathrm{H}$, Tsukada $\mathrm{H}$ and Oku N: T cell-independent B cell response is responsible for $\mathrm{ABC}$ phenomenon induced by repeated injection of PEGylated liposomes. Int J Pharm 392: 218-223, 2010.

28. Ishida T, Atobe K, Wang $\mathrm{X}$ and Kiwada H: Accelerated blood clearance of PEGylated liposomes upon repeated injections: effect of doxorubicin-encapsulation and high-dose first injection. J Control Release 115: 251-258, 2006. 
29. Ishihara T, Takeda M, Sakamoto H, Kimoto A, Kobayashi C, Takasaki N, Yuki K, Tanaka K, Takenaga M, Igarashi R, et al: Accelerated blood clearance phenomenon upon repeated injection of PEG-modified PLA-nanoparticles. Pharm Res 26: 2270-2279, 2009.

30. Liu Y and Lu W: Recent advances in brain tumor-targeted nano-drug delivery systems. Expert Opin Drug Deliv 9: 671-686, 2012.

31. Lin X, Gao R, Zhang Y, Qi N, Zhang Y, Zhang K, He H and Tang X: Lipid nanoparticles for chemotherapeutic applications: strategies to improve anticancer efficacy. Expert Opin Drug Deliv 9: 767-781, 2012.

32. Fang JY and Al-Suwayeh SA: Nanoparticles as delivery carriers for anticancer prodrugs. Expert Opin Drug Deliv 9: 657-669, 2012.

33. Battaglia L and Gallarate M: Lipid nanoparticles: state of the art, new preparation methods and challenges in drug delivery. Expert Opin Drug Deliv 9: 497-508, 2012.

34. Hofheinz RD, Gnad-Vogt SU, Beyer U and Hochhaus A: Liposomal encapsulated anti-cancer drugs. Anticancer Drugs 16: 691-707, 2005.

35. Agnihotri S, Gajadhar AS, Ternamian C, Gorlia T, Diefes KL, Mischel PS, Kelly J, McGown G, Thorncroft M, Carlson BL, et al: Alkylpurine-DNA-N-glycosylase confers resistance to temozolomide in xenograft models of glioblastoma multiforme and is associated with poor survival in patients. J Clin Invest 122: 253-266, 2012.

36. Russo M, Spagnuolo C, Tedesco I, Bilotto S and Russo GL: The flavonoid quercetin in disease prevention and therapy: facts and fancies. Biochem Pharmacol 83: 6-15, 2012.

37. Boots AW, Balk JM, Bast A and Haenen GR: The reversibility of the glutathionyl-quercetin adduct spreads oxidized quercetin-induced toxicity. Biochem Biophys Res Commun 338: 923-929, 2005

38. Boots AW, Li H, Schins RP, Duffin R, Heemskerk JW, Bast A and Haenen GR: the quercetin paradox. Toxicol Appl Pharmacol 222: 89-96, 2007.

39. Ferraresi R, Troiano L, Roat E, Lugli E, Nemes E, Nasi M, Pinti M, Fernandez MI, Cooper EL and Cossarizza A: Essential requirement of reduced glutathione $(\mathrm{GSH})$ for the anti-oxidant effect of the flavonoid quercetin. Free Radic Res 39: 1249-1258, 2005.

40. Lee SW, Kim HK, Lee NH, Yi HY, Kim HS, Hong SH, Hong YK and Joe YA: The synergistic effect of combination temozolomide and chloroquine treatment is dependent on autophagy formation and p53 status in glioma cells. Cancer Lett 360: 195-204, 2015.

41. Zheng H, Ying H, Yan H, Kimmelman AC, Hiller DJ, Chen AJ, Perry SR, Tonon G, Chu GC, Ding Z, et al: p53 and Pten control neural and glioma stem/progenitor cell renewal and differentiation. Nature 455: 1129-1133, 2008.
42. Lino MM and Merlo A: PI3Kinase signaling in glioblastoma. J Neurooncol 103: 417-427, 2011.

43. Fan QW, Cheng C, Hackett C, Feldman M, Houseman BT, Nicolaides T, Haas-Kogan D, James CD, Oakes SA, Debnath J, et al: Akt and autophagy cooperate to promote survival of drugresistant glioma. Sci Signal 3: ra81, 2010.

44. Ahmed F and Discher DE: Self-porating polymersomes of PEG-PLA and PEG-PCL: Hydrolysis-triggered controlled release vesicles. J Control Release 96: 37-53, 2004.

45. Cai S, Vijayan K, Cheng D, Lima EM and Discher DE: Micelles of different morphologies - advantages of worm-like filomicelles of PEO-PCL in paclitaxel delivery. Pharm Res 24: 2099-2109, 2007.

46. Ahmed F, Pakunlu RI, Srinivas G, Brannan A, Bates F, Klein ML, Minko T and Discher DE: Shrinkage of a rapidly growing tumor by drug-loaded polymersomes: $\mathrm{pH}$-triggered release through copolymer degradation. Mol Pharm 3: 340-350, 2006.

47. Kumar N, Ravikumar MN and Domb AJ: Biodegradable block copolymers. Adv Drug Deliv Rev 53: 23-44, 2001.

48. Shive MS and Anderson JM: Biodegradation and biocompatibility of PLA and PLGA microspheres. Adv Drug Deliv Rev 28: 5-24, 1997

49. Siepmann J and Göpferich A: Mathematical modeling of bioerodible, polymeric drug delivery systems. Adv Drug Deliv Rev 48: 229-247, 2001.

50. Chow TH, Lin YY, Hwang JJ, Wang HE, Tseng YL, Wang SJ, Liu RS, Lin WJ, Yang CS and Ting G: Improvement of biodistribution and therapeutic index via increase of polyethylene glycol on drug-carrying liposomes in an HT-29/luc xenografted mouse model. Anticancer Res 29: 2111-2120, 2009.

51. Lee JS, Ankone M, Pieters E, Schiffelers RM, Hennink WE and Feijen J: Circulation kinetics and biodistribution of dual-labeled polymersomes with modulated surface charge in tumor-bearing mice: comparison with stealth liposomes. J Control Release 155: 282-288, 2011

52. Dams ET, Laverman P, Oyen WJ, Storm G, Scherphof GL, van Der Meer JW, Corstens FH and Boerman OC: Accelerated blood clearance and altered biodistribution of repeated injections of sterically stabilized liposomes. J Pharmacol Exp Ther 292: 1071-1079, 2000

53. Ishida T, Ichikawa T, Ichihara M, Sadzuka $\mathrm{Y}$ and Kiwada $\mathrm{H}$ : Effect of the physicochemical properties of initially injected liposomes on the clearance of subsequently injected PEGylated liposomes in mice. J Control Release 95: 403-412, 2004. 